\title{
Vertigo and upside down vision due to an infarct in the territory of the medial branch of the posterior inferior cerebellar artery caused by dissection of a vertebral artery
}

\author{
N Charles, C Froment, G Rode, A Vighetto, F Turiman, M Trillet, G Aimard
}

\begin{abstract}
A 48 year old woman developed an acute vestibular syndrome associated with upside down vision a few hours after minor cervical trauma. Magnetic resonance imaging showed an ischaemic lesion in the territory of the medial branch of the posterior inferior cerebellar artery. An arteriogram showed a dissection of the left extracranial vertebral artery.
\end{abstract}

Since the advent of CT small cerebellar strokes are known to present as isolated vestibular, syndromes. $^{1-5}$ The pathophysiology of these labyrinthine-like syndromes has recently been clarified from the results of magnetic resonance imaging (MRI) and pathological studies..$^{5-7}$ In most cases they result from infarction associated with the medial branch of the posterior inferior cerebellar artery. ${ }^{67} \mathrm{We}$ report a case of such a stroke due to dissection of a vertebral artery after a closed head injury.

\section{Case report}

A 48 year old woman with no neurological history was in a car accident that resulted in mild trauma to her left shoulder and lateral neck. She complained of left shoulder pain, and paresthesias in the left thumb a few hours later. Neurological and general examinations showed nothing remarkable. Neither fracture nor dislocation was noted in a radiogram of the cervical spine. Twenty four hours after the accident, while at home, she suddenly experienced vertigo, nausea, and vomiting. She remained unable to stand or walk for four hours because of the vertigo. Six hours after the onset, she noted that her vision was upside down for all objects in her whole visual field; this lasted for 30 minutes. The vertigo spontaneously resolved in eight to 10 hours, but the dizziness and unsteady gait persisted, resulting in her being admitted to our hospital. Neurological examination disclosed a mild vestibular syndrome, with a rightward deviation when she walked with her eyes closed and a bilateral horizontal jerk nystagmus. There was neither dysarthria nor limb ataxia. A mild hypoesthesia of her left thumb was noted. Left biceps and brachioradialis reflexes were diminished.

She had mild neck stiffness but no pain. The rest of the examination showed nothing remarkable. The initial diagnosis was posttraumatic labyrinthine disturbance, with a C6 radiculopathy confirmed by electromyography. A CT was normal. However, because of the persistence of the vestibular syndrome for the next four days MRI was performed. On T2 weighted sequences there was a region of high signal, triangularly shaped, in the left cerebellum that affected the flocculus and the nodulus. Medulla and pons were apparently spared (figures 1 and 2). A four vessel angiogram disclosed a dissection of the extracranial left vertebral artery at C6 over 2 $\mathrm{cm}$ (figure 3(a)). She walked normally within a few days. Anticoagulant treatment (aspirin 500 mg a day) was started. Two months later, an angiogram showed persistent irregularities in the arterial lumen (figure 3(b)).

\section{Discussion}

Post-traumatic dissections of the extracranial vertebral artery are rare. They are common causes of vertebrobasilar ischaemic strokes in young adults. The clinical picture is often that of Wallenberg's syndrome associated with cervical pain. ${ }^{8-10}$ Their incidence is probably underrated as the causative trauma is often mild and the clinical picture commonly delayed

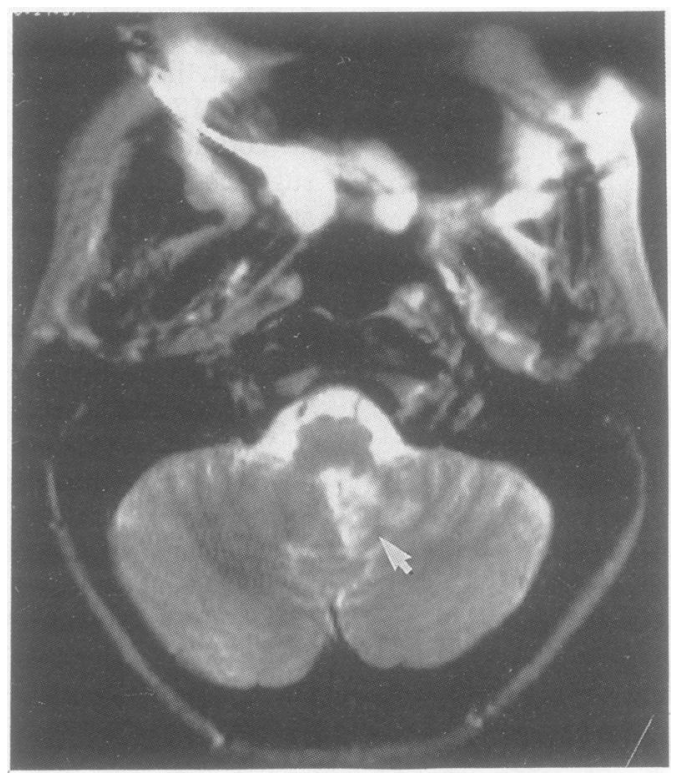

Figure 1 Left triangular high signal on T2 weighted MRI axial section of the cerebellum showing involvement MRI axial section of the cerebellum showing
of the flocculus (arrow) but not the medulla. 
Figure 2 High signal area on $T 2$ weighted axial section of the caudal cerebellum showing involvement of the nodulus (arrow).

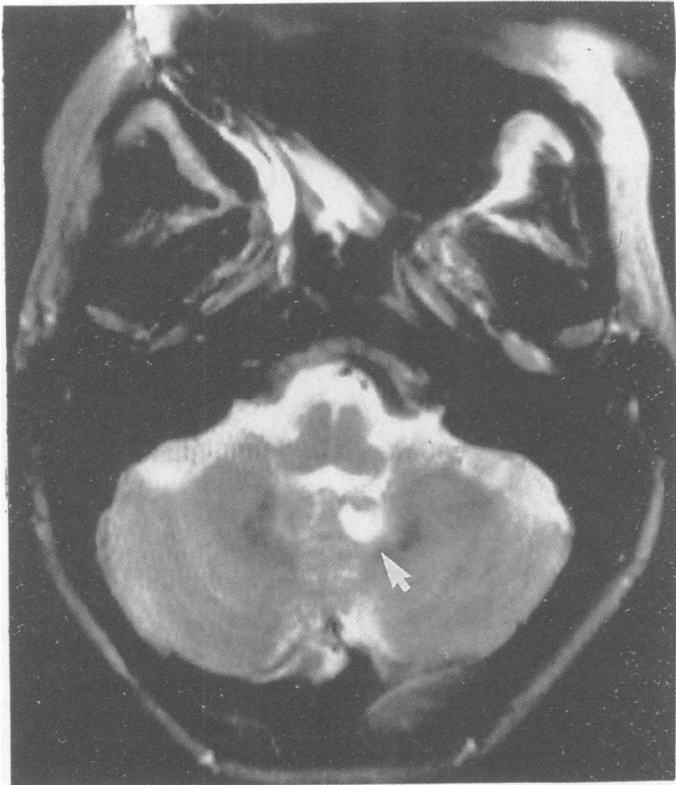

with respect to the onset of the trauma. ${ }^{112}$ In our case clinical presentation mimicked a labyrinthine lesion and there was no pain. MRI showed evidence of an ischaemic pure cerebellar stroke.

Until recently, the only cases of cerebellar infarct that were clinically recognised had pseudotumoural evolution. The advent of CT and MRI permitted the recognition of milder forms of cerebellar softenings, which currently seem to be the most common presentation. ${ }^{37}{ }^{13}$ Among these benign forms, a few isolated vestibular syndromes simulating labyrinthine lesions have been described. ${ }^{126714}$ Recently, Amarenco et al showed that these infarcts affect the territory of the medial branch of the posterior inferior cerebellar artery. ${ }^{6}$ This artery supplies a triangular area with a dorsal base and a ventral apex towards the fourth ventricle, well seen on MRI sections. This territory involves

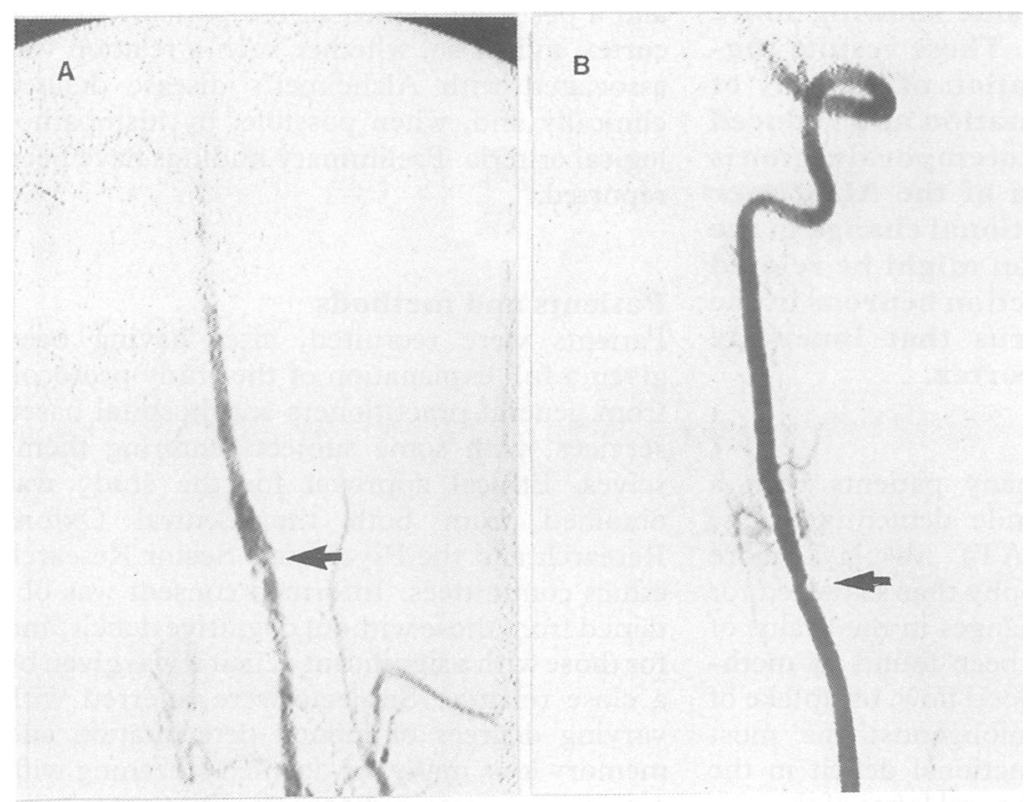

Figure 3 (a) Left vertebral arteriogram showing segmental irregular narrowing of the vertebral artery over $2 \mathrm{~cm}$ (arrow). (b) Left vertebral arteriogram two months later, showing persistence of dissection in lower part, and a small intraluminal defect corresponding to displaced intima (arrow). the internal part of the caudal cerebellar lobuli and the inferior vermis, mainly the nodulus. The flocculus is usually vascularised by the anterior inferior cerebellar artery. In 3\% of cases, however, the posterior inferior cerebellar artery also supplies the flocculus, ${ }^{615}$ as in the case of Duncan et al. ${ }^{1}$ In our case MRI findings suggested that both flocculus and nodulus were affected, probably because of common vascularisation by the posterior inferior cerebellar artery. The flocculonodular lobe receives direct projections from the labyrinth. Lesions of this complex represent a likely basis for dizziness, nystagmus, and vertigo.

Our patient also experienced upside down vision. The pathophysiology of this rare visual illusion is still unknown. Most authors emphasise the role of vestibulo-ocular disturbance, ${ }^{16}$ and this phenomenon has been described mainly in Wallenberg's syndromes ${ }^{17}$ and in other manifestations of vertebrobasilar ischaemia. ${ }^{17} 18$ Our case might suggest that this upside down vision could be due, at least in some cases, to an isolated lesion of the flocculonodular complex.

We emphasise that a vestibular syndrome following minor head trauma is not always a benign vestibular disturbance but may be a limited cerebellar infarct due to dissection of a vertebral artery.

1 Duncan GW, Parker SW, Miller Fisher C. Acute cerebellar infarction in the PICA territory. Arch Neurol 1975;32:364-8.

2 Guiang RL, Ellington OB. Acute pure dysequilibrium in cerebellar infarction. Eur Neurol 1977;16:11-5.

3 Samson M, Mihout B, Thiebot J, Segond G, Weber J, Proust B. Forme bénigne des infarctus cérébelleux. Rev Neurol (Paris) 1981;137:373-82.

4 Huang C, Yu Y. Small cerebellar strokes may mimic labyrinthine lesion. J Neurol Neurosurg Psychiatry 1985;48:263-5.

5 Amarenco P, Hauw JJ, Henin D, Duychaerts C, Roullet E, Laplane D, Gautier JC, Lhermitte F, Buge A, Castaigne $P$. Les infarctus du territore de l'artère cérébelleuse postero-inférieure. Etude clinico-pathologique de 28 cas. postero-inferieure. Etude clinico-pathol

6 Amarenco P, Roullet E, Hommel M, Chaine P, Marteau R. Infarction in the territory of the medial branch of the posterior inferior cerebellar artery. $J$ Neurol Neurosurg Psychiatry 1990;53:731-5.

7 Masson C, Cheron F. Infarct in the territory of the medial branch of the PICA. J Neurol Neurosurg Psychiatry 1990;53:1104-5.

8 Contamin F, Hauw JJ, Singer B, Josset P, Bianco C, Mignot $\mathrm{B}$, et al. Syndrome de Wallenberg par hémodissection (anéurysme disséquant) de l'artère vertébrale. Rev Neurol (Paris) 1982;138:337-43.

9 Senter HJ, Sarwar M. Nontraumatic dissecting aneurysm of the vertebral artery. $J$ Neurosurg 1982;56:128-30.

10 Mas JL, Bousser MG, Hasboun D, Laplane D. Extracranial vertebral artery dissections: a review of 13 cases. Stroke 1987;18:1037-47.

11 Schellhas KP, Latchaw RE, Wendling LR, Gold LHA. Lésions vertébro-basilaires survenant après manipulation cervicale. JAMA 1980;244:1450-3.

12 Rae-Grant AD, Lin F, Yaeger BA, Barbour P, Levitt LP, Castaldo JE. Post traumatic extracranial vertebral artery Castaldo JE. Post traumatic extracranial vertebral artery dissection with locked-in syndrome: a case with MRI documentation and unusually favorable

13 Scotti G, Spinnler H, Sterzi R, Vallar G. Cerebellar softening. Ann Neurol 1980;8:133-40.

14 Bogousslavsky J, Regli F. Latéro-pulsion axiale isolée lors d'un infarctus cérébelleux flocculo-nodulaire. Rev Neurol (Paris) 1984;140:140-4.

15 Lazorthes G. Vascularisation et circulation cérébrale. Paris: Masson, 1961.

16 Steiner I, Shahin R, Melamed E. Acute "upside-down" reversal of vision in transient vertebrobasilar ischemia. Neurology 1987;37:1685-6.

17 Hagström L, Hörnsten G, Silfverskiöld BP. Oculostatic and visual phenomena occurring in association with Wallenberg's syndrome. Acta Neurol Scand 1969;45:568-82.

18 Halpern L, Kidron DP. Sensorimeter induction syndrome in unilateral disequilibrium. Neurology 1954;4:233-40. 